\title{
Opportunities and Challenges: Discussion on Improving Judge Training in the Post System Reform
}

\author{
Wenjie He \\ China University of Political Science and Law \\ Beijing, China
}

\begin{abstract}
The special position of a judge in judicial practice requires that the judge must be professional, specialized and talented. However, currently there are many problems existing in the judge training, which has caused a huge gap between the judge quality and judicature expected by the people. The post system reform raises that the judge should be standard, specialized and professional, facing the situation, we can conduct the reform on the judge training through three aspects: build a systematic and neutral trainer for the judge training; establish special facilities for the judge training; perfect professional courses for judge training. After receiving the training, judges will own professional moral, independent abilities of judgment, special knowledge to interpret laws to the parties concerned so as to keep the judicature authoritative.
\end{abstract}

Keywords-judge training; status quo; post system reform; improvement

\section{INTRODUCTION}

A judge is an important part for the judicial practice, and the personal accomplishment and professional knowledge that the judge owns will directly determine the effect of law enforcement. At the beginning of China's foundation, the judicial system was newly established, yet there was no judicial training, facing such a situation, the reform and training attempts were started in the country. Due to the special positions of judges in judicial practice, they are required to be professional and specialized and even talented according to the development so as to correctly deal with judicial disputes and keep the judicature in a long term judicial practice. Yet there is a large gap in reality especially going with the advancement of society, economy and technologies, the independence when subjective or objective has got a leap improvement, yet due to uncertainty of sources for judge faculties, it is unable to protect the basic professional knowledge and skills of judges, which is far to meet the expectation of the people, and the judicial authority is a far thing to think. Facing such a situation, the judge training fails to meet the practice, judges are integrated to public servants for management, whose induction training is done with the public servant training, finally it has caused the inconsistence between judges' professional characteristics and their professional moral, value, judicial concept, skills and behaviors. This article tries to discuss the significance that the judge training should have, analyze problems existing in the judge training, and consider the breakthrough possible for the judge training in the post system reform.

\section{DEFINITION OF JUDGE TRAINING}

The judge training refers to not the legal education and other basic education before being judges. Clause 2 of Rules for Judge Training of the People's Republic of China provides that the judge training consists of probationary judge, post training, promotion training and post-continued training. ${ }^{1}$ Therefore, the judge training is a professional education, which aims at special group and special education related to practice. With such professional orientation, What should the judge training be? First of all, the professional education shall serve the judgment work at courts, which is directive goal, with the goal achieved, it will come to the effect of judicial practice. Hence, the judge training shall be focused on the uniform law concepts for judges, renewal of professional knowledge structure, and understanding to the legislative spirit as well as the grasp of applying laws. Major forms for the judge training are necessary parts to achieve the training contents. Accordingly when discussing the judge training, we should start with trainer, form and contents to investigate the defects existing in the training and any possibility for breakthrough. Matching with judicial system and the expectation of the people to the judicature, the judge training can be achieved under the professional and systematic professional training, after receiving the training, judges will own professional moral, independent abilities of judgment, special knowledge to interpret laws to the parties concerned so as to keep the judicature authoritative.

\section{Status QUO OF JUdGE TRAINING}

Sources of judicial officials especially judges in China have always been in contradiction with their professionalism and a large number of non-professionals who receive no legal education and have no judicial skills are arranged to work at courts, and the vague judge admission system has caused great difference in the professional quality of judges. Though the judge training has been developing, yet it still becomes difficult to meet the judicial practice, the basic legal quality of judges is becoming far and far to meet the expectation of the people to the judicature, and the contradiction is obvious. The professional training on judges cannot really improve the professional level of judges, at present, main problems arising out of the judge training include:

${ }^{(1)}$ Rules for Judge Training of the People's Republic of China, revised on Mar 30, 2006. 


\section{A. Local and Administrative Trainers for Judge Training}

Clause 1 of Rules for Judge Training of the People's Republic of China provides, in accordance with Judges Law of the People's Republic of China and the Public Servant Law of the People's Republic of China, the rules are hereby formulated. ${ }^{(2)}$ Therefore, that the judge training is integrated to the public servant training is of administration. After passing public servant examinations, a judge will become a member of court officials, first of all, the judge needs to participate in the public servant training which is led administration organs, the training system is completely separated from the judicial characteristics, and the judge training and other trainings are not coordinated and difficult to distinguish. Clause 8 of Rules for Judge Training provides the competent departments of supreme people's court and higher people's court shall take charge of judge training-related plans, management and coordination. Competent departments of intermediate people's court and grass-root people's court shall take charge of organizing and completing the training tasks delivered by above leadership, and organize the post-continued training of judges at the areas under their jurisdiction. ${ }^{(3)}$ At present, the judge training is predominated by national judge colleges established by the Supreme People's Court, centered on provincial judge colleges and supported by local judge training agencies. The framework is mainly responsible for training of probationary judges, office, promotion and post-continuance. For the judges have a large base, and only few can have chances to receive training at national judge colleges, and only the provincial and city-level judge training agencies can provide judge training actually, and there are many problems in the localization. One of the directive influences of the localization is non- systemaltization and the difference in juridical concepts. Reflected on juridical cases, it can be seen that different judgments occur for the same case. The localization of trainers will limit the legal concepts of judges, doing bad to the formation of professionalism.

\section{B. Improper Faculty Structure for Judge Training, Most Are Formalistic}

In practice, courts pay little attention to the judge training, due to more cases but few judge, the judges have to make selfstudy within limited time, rarely receiving systematic, specialized and professional training. The judge training stated in Rules for Judge Training are mostly done in form. Within limited training, even they receive some professional knowledge and skills usable yet they are limited by the inadequate faculties. Current training modes are almost the same as general legal training. However, the requirements of judge training on teachers are far compared to general legal education. Obviously the judge training has higher requirements, for it gets involved with the direct application of legal concepts and laws. Teachers who are engaged in the judge training should not only have solid legal theories, but also have rich experience in judicial practice, as well as have abilities to summarize and turn practice and theories into each

\footnotetext{
(2) Rules for Judge Training of the People's Republic of China, revised on Mar 30, 2006

${ }^{(3)}$ Rules for Judge Training of the People's Republic of China, revised on Mar 30, 2006.
}

other. Actually during the judge training, generally the teachers are directly coming from universities, who are not professional professors but lecturers, as such it is meaningless for the judge training, or those who are from practical departments, having no complete legal theories, are arranged to teach how the laws are used, yet they know little of the intention of legislation. Especially in practice, judges who are trained are likely to find that they are by taught by the judges who are almost the same as them in skills. In the meantime, due to the busy work, the judge training is in a high absence, the whole court system has not formed a correct understanding of the training, facing the pressure of higher cases, the so -called raining is done completely in the form, which is far to achieve the goal of judge training.

\section{Imperfect Contents for Judge Training}

The training is to improve the comprehensive quality of judges, however, at present, the contents used for judge training are basically copying the education mode of law schools, and the training contents have no targets, failing to exert the rational functions to train judges in practice. ${ }^{(4)}$ The course design has no clear goals, having little understanding of professionalism, basically the legal knowledge related to the basic legal education is taught, and most trainings are single and temporary, having no an overall design for the judge training. Currently the training does not value the cultivation of judicial concepts, besides, there are no contents taught about legal connotation, professional moral, judicial disciplines and so on. Most of the trainings, especially those at grass-roots courts, are specific task training, and main contents are the newly promulgated laws, regulations and judicial interpretation, highly practical, yet no attentions are paid to concepts behind the release of laws and regulations and judicial interpretation. The focus of trainings is limited to the latest content and knowledge of a departmental law, and those who are trained are also officials related to the departmental law, yet there are also flows between the members of the court, judges who are engaged in civil judges or criminal judges may not be always engaged in the same judgment. The irrational training course setting is unable to improve the judicial skills of judges especially the grass-root ones. Judges are passive to participate in trainings, having no abilities got to summarize the training contents, unable to get theories and general rules out of their judicial practice and experience and get profits from it. In general, the contents of judge training ignore the training on judges' professional thinking and skills.

However, the problems are not all the problems for the judge training; there are still other problems such as little attention to judge training, lack of pre-service training and so on.

\footnotetext{
(4) Lyu Zhongmei, Discussion on Rational Civilization of Legal Practice and Legal Education Reform - at the perspective of building a special judge training system, Journal of Hubei University of Economics, 2010, (3)
} 


\section{OPPORTUNITIES FROM THE JUdGE POST SYSTEM REFORM}

The CPC 17th National Congress raised "We need to deepen the reform of the judiciary system, optimize the distribution of judicial functions and powers, standardize judicial practices, and build a fair, efficient and authoritative socialist judiciary system to ensure that courts and procuratorates exercise their respective powers independently and impartially in accordance with the law." Dec 18, 2014, the CPC Political and Legislative Affairs Committee approved the judicial reform programs in seven pilot provinces and cities, from then on, the judicial system reform was launched at all levels, including classification management of judicial officials, judicial responsibility system, judicial officials security system, unified control over personnel, property and materials at local courts, and procuratorates below provincial level. Execute management systems over judges and prosecutors, different from the ordinary public servants; establish post systems for judges and prosecutors, and arrange high-quality talents to deal with cases. On Jul 31, 2013, in Shanghai, The Implementation Program for Pilot Work of Juridical System Reform at Shanghai Higher Court pointed out, the goal of post system reform of judges is to "Keep the court team in a development standard, specialized and professional" "5). In the meantime, the juridical system reforms in other provinces all establish a goal to keep the court officials standard, specialized and professional. The goal is just what the judge training expects, the post system reform and judge training share the same goal. The problem is, Could the judge training which is not valued catch the chance of the post system reform to achieve the improvement?

\section{THOUGHT OF JUDGE TRAINING IMPROVEMENT}

Starting from the goal of the post system reform which requires judges to be standard, specialized and professional, in order to achieve the synchronous development supporting the judge training, considerations can be made for improvement from the three points as follows:

\section{A. Consider the Systematic and Neutral Trainers for Judge Training}

In order to achieve the local and administrative goals of judge training, it needs to set up a training system to achieve the standard management. Renovate the current training management, follow the existing "unified control over personnel, properties and materials below provincial level" in the existing judicial system reform, actively promote the courts below provincial level for unified control over personnel, property and materials, establish a single court training system which is separated from the local personnel training system, and ensure the unified implementation of judge training activities in a province. In the meantime, clarify the functional orientation of training departments at courts at all levels, regulate the supervision and guidance of the training departments at below and above levels. Make it neutral white de-administrating. The neutral training will make the judge training more scientific, rational and more adaptable to professional characteristics of judges. With the existing conditions, special departments of above courts may launch the training, or three-level courts will establish a joint evaluation committee in charge of the training.

\section{B. Consider to Specialize the Judge Training Team}

In order to avoid the judge training from being done in the form, we need to build a targeted professional training faculty team. The requirements on professional education of judges are higher than the basic education of general legal disciplines. The Teachers who are engaged in the judge training shall have not only solid foundation of law theories but also rich experience in judicial practice, besides, the two shall be integrated and indispensable. We should not be focused on theories only or the practice only. We have to follow the law of judicial judgment, establish a clear standard and mechanism for selection, strictly follow the standards to select competent teachers for the judge training and set up a stable faculty team, and achieve a targeted training of judges.

\section{Consider to Professionalize the Contents of Judge Training}

In order to meet the post system reform, the training which is based on the current law knowledge and new clauses must be changed. The contents of judge training shall not only consider the juridical system, aiming at the actual judgment, but also improve the individual quality of judges. On the content setting, it shall contain courses related to the basic professional quality of judges, with the legal knowledge and clauses grasped, it needs to deepen the understanding of legal concepts and value contained inside laws. In the meantime, clarify the relations and mutual roles between society, economy, politics, culture and laws, truly protect the social justice and order, knowing what we should do to keep the juridical fairness. Based on it, we need to strengthen the exercise of professional thought of judges, which differ with that of common people, it needs to form a sound legal thought mode on the basis of special thought training, able to engage in the judgment affairs with skilled legal thoughts. Skillfully grasp legal languages, clarify the value of procedures, learn legal interpretation and reasoning methods and master rules of evidences. While applying legal thought flexibly, the judge training shall contain contents related to juridical skills, with the juridical skills obtained, the judges can grasp skills in the juridical practice and achieve the connection of juridical practices. Actually juridical skills and legal thoughts just refer to technique and method, only one of which cannot go normally, so the two must be integrated so as to guarantee the judges' professional level.

\section{CONCLUSION}

With the judge training improved, the in-service training of judges is expected to enable them to reach professional moral, owning abilities of independent judgment and finally keeping the judicature authoritative.

\footnotetext{
(5) Jul 31, 2014, The Implementation Program for Pilot Work of Juridical System Reform at Shanghai Higher Court.
} 


\section{REFERENCES}

[1] Rules for Judge Training of the People's Republic of China, modified on Mar 30, 2006.

[2] The Implementation Program for Pilot Work of Juridical System Reform at Shanghai Higher Court on Jul 31, 2014

[3] Lyu Zhongmei, Discussion on Rational Civilization of Legal Practice and Legal Education Reform - at the perspective of building a special judge training system, Journal of Hubei University of Economics, 2010, (3) 